\title{
REFLEXIÓN EN TORNO A LAS NUEVAS PRÁCTICAS DE SUBORDINACIÓN DEL SER ANTE SUS PROPIAS CREACIONES
}

\author{
Reflection on the new practices of subordination of the being to its own \\ creations
}

Reflexão relativa às novas práticas de subordinação do ser em suas próprias

criações

\author{
Araceley Berny \\ Universidad Nacional Autónoma de México \\ berny@unam.mx
}

\section{Resumen}

También a la filosofía compete la reflexión y llamada de atención en torno a la recuperación del equilibrio que pro-cura la vida ahí donde la ceguera de una humanidad sustituye la vida por ilusiones fabricadas en el imperio de la técnica, la ciencia y la tecnología. De ahí que la verdadera preocupación de quien aquí suscribe recae en las actitudes humanas, porque lo verdaderamente preocupante es la desaparición de la capacidad de asombro, de la capacidad creadora, de la capacidad de entrega enamorada a la vida en sus manifestaciones todas. Precisamente porque no se trata de reflexionar en torno a un determinismo tecnológico, sino de pensar la conformación de las nuevas maneras de relacionarse del ser, en donde éste no pierda de vista su papel creador y constitutivo y no fungiendo como mero soporte al servicio de las tecnologías.

Palabras clave: Tecnología. Ficción. Creatividad.

\begin{abstract}
Philosophy is also responsible for the reflection and call for attention around the recovery of the equilibrium that pro-cured life where the blindness of a humanity replaces life with illusions manufactured in the empire of technology, science and technology. Hence, the real concern of those who subscribe here falls on human attitudes, because what is truly worrying is the disappearance of the capacity for astonishment, of the creative capacity, of the capacity to surrender in love to life in all its manifestations. Precisely because it is not a question of reflecting on a technological determinism, but of thinking about the conformation of the new ways of relating to being, in which the being does not lose sight of its creative and constitutive role and does not act as mere support to the service of technologies.
\end{abstract}

Keywords: Technology. Fiction. Creativity. 


\section{Resumo}

Também para a filosofia é a reflexão e o apelo à atenção em torno da recuperação do equilíbrio que vive a vida onde a cegueira de uma humanidade substitui a vida por ilusões fabricadas no império da tecnologia, ciência e tecnologia. Assim, a preocupação real da pessoa aqui se inscreve nas atitudes humanas, porque o que é verdadeiramente preocupante é o desaparecimento da capacidade de admiração, da capacidade criativa, da capacidade de entrega no amor à vida em suas manifestações.Precisamente porque não se trata de refletir sobre um determinismo tecnológico, mas pensar na conformação dos novos modos de relacionar o ser, onde ele não perde de vista seu papel criativo e constitutivo e não serve de mero apoio a serviço da sociedade. tecnologias

Palavras-chave: Tecnologia. Ficção. Criatividade.

Suponemos que contamos con la capacidad cognitiva y que ésta descansa en el intelecto: es suficiente una mirada objetiva al modo de vida contemporáneo, para percatarnos de la capacidad destructiva de que sí somos capaces gracias, quizás, a la inteligencia.

El análisis genealógico del conocimiento y la crítica de la noción de verdad nietzscheanos, ponen en entredicho la suficiencia del intelecto humano para acceder a "La Verdad". El filósofo de Röcken parte de la sospecha de que el conocimiento es un invento del intelecto humano, necesario para mantener la supervivencia en un mundo que atenta contra su existencia; al depender únicamente del intelecto el ser humano vive asido a convenciones, las que le asegurarán su afable pertenencia a la sociedad:

El hombre nada más que desea la verdad en un sentido análogamente limitado: ansía las consecuencias agradables de la verdad, aquellas que mantienen la vida: es indiferente al conocimiento puro y sin consecuencias e incluso hostil frente a las verdades susceptibles de efectos perjudiciales o destructivos. (Nietzsche 1990: 21)

Nietzsche señala (1990: 23), que las verdades son metáforas que están apoyadas en ficciones necesarias, son meros acuerdos humanos a partir de la "equiparación de casos no iguales"; donde la verdad surge a manera de equipamiento, para pervivencia de la humanidad:

En algún apartado rincón del universo centelleante, desparramado en innumerables sistemas solares, hubo una vez un astro en el que animales inteligentes inventaron el conocimiento. Fue el minuto más altanero y falaz de la "Historia Universal": pero, a fin de cuentas, sólo un minuto. Tras breves respiraciones de la naturaleza el astro se heló y los animales inteligentes hubieron de perecer. Alguien podría inventar una fábula semejante pero, con todo, no habría ilustrado suficientemente cuán 
lastimoso, cuán sombrío y caduco, cuán estéril y arbitrario es el estado en el que se presenta el intelecto humano dentro de la naturaleza. [...] (el intelecto), sólo ha sido añadido precisamente como un recurso de los seres más infelices, delicados y efímeros, para conservarlos un minuto en la existencia [...] (Nietzsche, 1990: 71s).

Nietzsche sostiene que el intelecto sólo es el salvoconducto para enfrentar la disputa por la supervivencia, en un medio que resulta hostil y amenazador para el ser humano. Por otra parte, y dado el impulso gregario del hombre es que se ve forzado a crear acuerdos que posibiliten la convivencia, Schopenhauer lo describe de este modo, mediante una métafora:

Un grupo de puercoespines se apiñaba en un frío día de invierno para evitar congelarse calentándose mutuamente. Sin embargo, pronto comenzaron a sentir unos las púas de otros, lo cual les hizo volver a alejarse. Cuando la necesidad de calentarse les llevó a acercarse otra vez, se repitió aquel segundo mal; de modo que anduvieron de acá para allá entre ambos sufrimientos hasta que encontraron una distancia mediana en la que pudieran resistir mejor -Así la necesidad de compañía, nacida del vacío y la monotonía del propio interior, impulsa a los hombres a unirse; pero sus muchas cualidades repugnantes y defectos insoportables les vuelven a apartar unos de otros. La distancia intermedia que al final encuentran y en la cual es posible que se mantengan juntos es la cortesía y las buenascostumbres. (Schopenhauer, 2013: 665)

Es por esta razón que el hombre recurre a la invención de convenios que pretenden generalidad y valides para todos:

... el hombre, tanto por necesidad como por hastío, desea existir en sociedad y gregariamente, precisa de un tratado de paz [...] Este tratado de paz conlleva algo que promete ser el primer paso para la consecución de ese misterioso impulso hacia la verdad. En este mismo momento se fija lo que a partir de entonces ha de ser «verdad», es decir, se ha inventado una designación de las cosas uniformemente válida y obligatoria ... (Nietzsche, 1990, 20)

En ese sentido, lo único valioso para decidir si algo es verdadero, es su carácter consensual, toda verdad es mentira consensuada, porque no importa qué tan mentiroso sea lo que se esté aseverando: siempre y cuando se halla acordado como «verdad» así será designado. El hombre huirá del perjuicio, más que de la mentira, dice Nietzsche, el vivir en comunidad le procura condiciones agradables, y ser expulsado de su seno le acarrea consecuencias perniciosas, por lo que resulta claro que “... la mentira está permitida, en los 
casos en que resulta agradable: la belleza y el encanto de la mentira siempre que ésta no perjudique. (Nietzsche, 2000: 41)

Dado lo difícil que resulta para el individuo mantenerse aislado, ya sea por aburrimiento o por la necesidad de obtener los beneficios propios del vivir en comunidad, aceptará acuerdos que le propiciarán la convivencia y supervivencia. Dichas normas y acuerdos, siendo comunes para todos, suponen la disolución de conflictos entre individuos y la erradicación de la anomia.

Así surge la verdad entre los seres humanos, que se fragua mediante acuerdos, los que fungen como el impulso hacia la concreción de un mundo común; él habla de "ese misterioso impulso hacia la verdad" (Nietzsche, 1990: 20); verdad que responde a intereses y necesidades sociales, y se establece a partir de la regulación y adecuación con su entorno, para conseguir armonía, pero sobre todo, uniformidad.

Una vez que el hombre se ha comprometido con esos acuerdos, supone que está en posesión de la verdad, y se asume de facto, en posesión del conocimiento.

En este sentido, nuestro conocimiento es una ilusión inventada como medida de salvación humana, la ilusión del conocimiento es una condición humana que posibilita vivir.

Es mediante el ejercicio creativo del intelecto como se configura el mundo. Al aceptar la correspondencia entre la denominación y las cosas mismas es como se designa lo que las cosas son, y a partir de estas designaciones, se fijan y se atan las cosas a los términos en condiciones colectivas.

De la realidad, de las cosas, dice Nietzsche, únicamente tenemos aquello que nosotros mismos les hemos impuesto: sus nombres, que son el resultado del recorte arbitrario con que seleccionamos ciertas características "generales", delimitamos, definimos y distinguimos de la naturaleza particularidades, equiparamos, etiquetamos y luego nombramos, tomando la parte por el todo en un intento de crear un punto de apoyo entre nosotros y el mundo, para finalmente adherir la inamovible etiqueta que fijará y determinará lo que la cosa, teóricamente, es.

Pero de las cosas, dice Nietzsche, el intelecto sólo puede conocer sus efectos, nunca su esencia; de ahí que la verdad sea "equiparación de casos no iguales", mero montaje, ilusión, interpretación, donde creemos que por haberlo etiquetado y seleccionado "todo" ya se es partícipe y propietario del conocimiento, de la verdad: 
¿Qué es entonces la verdad? Una hueste en movimiento de metáforas, metonimias, antropomorfismos, en resumidas cuentas, una suma de relaciones humanas que han sido realzadas, extrapoladas y adornadas poética y retóricamente y que, después de un prolongado uso, un pueblo considera firmes, canónicas y vinculantes; las verdades son ilusiones de las que se ha olvidado que lo son; metáforas que se han vuelto gastadas y sin fuerza sensible, monedas que han perdido su troquelado y no son ahora ya consideradas como monedas, sino como metal. (Nietzsche, 1990: 25)

La verdad no sería sino la obligación de mentir de acuerdo a convenciones previas, ilusiones expresadas a través de metáforas, metaforizaciones arbitrarias respecto al mundo, conceptualizaciones inventadas; se trataría de un conocimiento fundado en nombres, priorizando y escogiendo subjetivamente y por imposición o “acuerdo social”, nombrando tan sólo recortes y seleccionando cualidades.

La crítica nietzscheana se dirige contra nuestra creencia de que por haberle dado nombre a las cosas, sepamos lo que son, suponemos que poseemos el conocimiento de las cosas y emitimos juicios desde esa creencia de posesión de la verdad. Nombrar, construir y constituir un lenguaje, resulta necesario para poder fijar una relación estable y de participación que resulte efectiva y conveniente para la especie, para ello se toman los nombres, las nociones establecidas. Mas no por lo anterior, sabemos ya lo que las cosas son. Para construir y constituir el lenguaje, se toman como referencia y cimientos los conceptos, que surgen a partir de la clasificación antropocéntrica. Ésta es arbitraria, pero es la única de la que somos capaces. Es con base en ciertas repeticiones de las características de las cosas que suponemos una identidad, eliminamos diferencias e igualamos, creyendo que con ello ya sabemos lo que las cosas son:

¡Cómo podríamos decir legítimamente, si la verdad fuese lo único decisivo en la génesis del lenguaje, si el punto de vista de la certeza lo fuese también respecto a las designaciones, cómo, no obstante, podríamos decir legítimamente: la piedra es dura, como si además captásemos lo "duro" de otra manera y no solamente como una excitación completamente subjetiva! (Nietzsche, 1990: 22)

Ello posibilita desgana y falta de compromiso al asirse de un mundo prefabricado, moldeado por otros, devieniendo así en un lamentablemente cómodo recipiente, depositario de frases y opiniones ajenas:

... nosotros, los modernos, no tenemos nada propio; tan solo en cuanto rellenándonos y sobrerrellenándonos de épocas, costumbres, artes, filosofías, religiones y conocimientos extraños, somos objetos dignos de consideración, es decir, enciclopedias ambulantes... (Nietzsche, 1994: 73) 
Habría entonces, una subordinación de la personalidad individual a la etiqueta. Ya que, para que en este mundo el hombre exista ha de estar etiquetado. En este sentido, la crítica nietzscheana se dirige a las actitudes humanas que no son capaces de crear y recrear su ser individual:

Hermano mío, si tienes una virtud, y esa virtud es la tuya, entonces no la tienes en común con nadie.

Ciertamente, tú quieres llamarla por su nombre y acariciarla; quieres tirarle de la oreja y divertirte con ella.

¡Y he aquí que tienes su nombre en común con el pueblo y que, con tu virtud, te has convertido en pueblo y rebaño!

Harías mejor en decir: «inexpresable y sin nombre es aquello que constituye el tormento y la dulzura de mi alma, y que es incluso el hambre en mis entrañas».

Sea tu virtud demasiado alta para la familiaridad de los nombres: y si tienes que hablar de ella, no te avergüences de balbucear al hacerlo. (Nietzsche, 1989: 63)

Él apuesta por enriquecer nuestro modo de conocer, no empobrecerlo quedándonos únicamente con los datos de la razón; porque, en el acto de conocer es necesaria la interacción entre la razón y los sentidos: esa mezcla rara que no da ninguna certeza definitiva de qué asirse y que se recrea de manera constante, dando cabida a la intuición:

... el hombre intuitivo, aposentado en medio de una cultura, consigue ya, gracias a sus intuiciones, además de conjurar los males, un flujo constante de claridad, animación y liberación. Es cierto que sufre con más vehemencia cuando sufre; incluso sufre más a menudo porque no sabe aprender de la experiencia y tropieza una y otra vez en la misma piedra en la que ya ha tropezado anteriormente. Es tan irracional en el sufrimiento como en la felicidad, se desgañita y no encuentra consuelo... (Nietzsche, 1990: 37)

Precisamente por no contar con un almacén donde acumular datos es que se tiene la capacidad de vivir intensamente cada nueva experiencia como única e irrepetible; el pensador apuesta por experienciar, ${ }^{1}$ sin prejuicios que petrifiquen el asombro y la sorpresa; permitiendo la interacción entre la razón y la pasión, "estomacal y cerebralmente”.

De acuerdo con la reflexión nietzscheana, el hombre se dedicó a clasificar y delimitar arbitrariamente, sin cuestionarse sobre su capacidad cognitiva y creativa, por lo que nuestras verdades son necesarias, pero al fin y al cabo, falsas: 
"Croyez-moi mon ami, I'erreur aussi a son mérite"2 ... Prescindir de la ficción y llevar la exigencia de la veracidad al extremo sería empujar a la humanidad al suicidio. Es preciso, pues, si queremos vivir, utilizar la mentira, aunque ahora, eso sí, con conciencia de que lo es; ... tenemos que seguir engañando, pero no debemos - no podemos- ya por más tiempo continuar engañados por nuestros propios engaños; nuestra exigencia de veracidad así nos lo impone. (Nietzsche, 1995: 21)

Estar conscientes de que estamos enredados en nuestras metáforas, nos da la certeza de que el lenguaje es lo único con lo que contamos al momento de argumentar y al momento de relacionarnos con el mundo y con nosotros mismos. A partir de esa conciencia el individuo puede re-crear constantemente su mundo, y en ese juego creativo encontrar el más lúdico amor a la existencia. Si pretendemos "conocer" la naturaleza y el mundo en general, ello sólo será posible desde nuestros moldes conceptuales:

La lógica no es más que la esclavitud en los lazos del lenguaje. Ahora bien, el lenguaje incluye un elemento ilógico, la metáfora. La primera fuerza determina una equiparación de lo desigual y, por tanto, es efecto de la fantasía. Esta es la base de la existencia de los conceptos, de las formas, etc. "Leyes de la naturaleza". Simples relaciones recíprocas y respecto del hombre.

El hombre como medida definitiva y firme de las cosas

En cuanto lo imaginamos flúido (sic) y oscilante, cesa la rigidez y las leyes de la naturaleza. (Nietzsche, 2000: 105)

En todo lo anterior lo que está en juego, es que ignoramos muchos principios evolutivos y olvidamos que muchos procesos "humanos" son copiados de la naturaleza. ${ }^{3} \mathrm{La}$

\footnotetext{
${ }^{1}$ Me permito jugar con una traducción el verbo alemán erfahren que no sólo significa "experimentar" sino también "absorber las experiencias vitales" que de esta manera producen cambios ontológicos.

${ }^{2}$ En español: Créame mi amigo, el error también tiene su mérito. Frase de Voltaire citada por Dolores Castrillo Miran, en su prólogo a Humano demasiado humano, de F. Nietzsche.

${ }^{3}$ Podemos encontrar otro ejemplo de lo expuesto en la última novela de Gustave Flaubert Bouvard y Pécuchet, donde dos parisinos que trabajan como copistas se retiran al campo después de recibir una cuantiosa herencia, compran una granja y se dedican a tratar de entender las ciencias: ¡todas! Leen manuales, monografías, libros de todo tipo y tratan de aplicar sus conocimientos, pero fallan en la práctica porque a veces sí funciona y a veces no. Aunque los libros traten de exactamente lo mismo, cada autor presenta su verdad como la última y definitiva sin que exista correspondencia alguna y sí demasiadas incongruencias, ello continúa así en todas las ciencias: matemática, química, historia, filosofía, etc. Así es como Flaubert muestra la debilidad y la fuerza del entendimiento humano, el cúmulo de contradicciones en las creencias y explicaciones, que prueban y documentan el saber del mundo. Cada autor describe el funcionamiento del mundo de manera arbitraria, cada autor, desde su perspectiva, define de un modo u otro, totalmente distinto, el conocimiento; mas imperan las contradicciones entre autores, causas, normas, etc. Los protagonistas de la novela se pierden en abstracciones, se asen de incertidumbres, excepciones a toda regla y contingencias, su decepción es tal que abandonan todo intento por probar y conocer, ya que en esos términos, las ciencias no sirven para nada y sirven para todo. De ahí que recuperan su antigua profesión y copian manuales enteros permanentemente, como si ése fuera el único quehacer de la ciencia y el único método de conocimiento al que podemos acceder: mediante la recopilación del saber del mundo -todo- en copias.
} 
ventaja de conceder carácter absoluto a los conceptos, es que se eximen las responsabilidades, en ese sentido Nietzsche critica al hombre por haber cedido su capacidad de crear, de recrear, metaforizar y verterse para sólo funcionar mientras se funde-con el todo de lo aparentemente real, con lo preestablecido: ello apunta al detrimento de la actividad creativa; asumir como real a las "sombras de las sombras" en palabras del literato austriaco Joseph Roth, y sucumbir ante el imperio de los medios, ceder el propio preferir, apagar la autoconciencia, terminaría produciendo el anquilosamiento del ser, porque el sistema mecanizado subordina al trabajador, deviniendo éste en un eslabón más dentro de la cadena de producción.

La tarea de la filosofía es la de propiciar la reflexión orientada a recuperar la propiedad de vida consciente; la que poco a poco se ha sometido ante la impersonalidad que domina en el imperio de la inmediatez, de la ciencia y la tecnología, tener la conciencia de que los aparatos que vienen a facilitar nuestra pervivencia no deberían obstaculizar, regular y encerrar la experiencia de asir y hacer cada vivencia: propia.

De ninguna manera esta reflexión pretende condenar las creaciones humanas, ya sean metafóricas, cognitivas, técnicas, tecnológicas o científicas, como tampoco pretende un análisis valorativo; esta reflexión descansa en el ser del hombre, en sus apetitos, preferencias y cualidades creativas; en el riesgo de que sea el mismo ser humano quien renuncie a su capacidad de decisión y de autosuficiencia para tan sólo subyugarse a la ilusión por la fascinación que los desarrollos le producen al desresponsabilizarse de su propias creaciones.

Siguiendo este orden de ideas, cabe mencionar que Joseph Roth sostiene que los nombres dados a las cosas, al ser equiparables se tornan en sonidos sin forma (Roth, 2002: 24), con lo que se consigue la pérdida de las designaciones, de los convencionalismos y acuerdos con que se había conferido certeza al nombre y consolidado la metáfora:

De hecho, ya no reconocemos desde hace mucho, la esencia y el aspecto de las cosas con que nos encontramos. Lo mismo que quienes padecen una ceguera física, tenemos sólo nombres para todas las cosas de este mundo que ya no vemos. ¡Nombres! ¡Nombres! Sonidos sin forma, ropajes vacíos para fenómenos irrepresentables, es decir, sin cuerpo y sin vida. ¿Son formas? ¿Son sombras? [...] Damos nombres falsos a cosas verdaderas. En nuestros pobres cerebros resuenan sonidos huecos; ya no sabemos con exactitud qué nombre ha de llevar cada cosa. [...] Sólo tenemos los nombres y las designaciones para las formas, los colores y los tamaños. (Roth, 2002: 24)

Entonces encontramos la falsificación de la metáfora, es decir, se trata ahora de recurrir a ficciones de una ilusión, de una realidad de por sí falseada, que mantenga esa 
necesidad nuestra de renuncia: a la individualidad, al compromiso y responsabilidad que vivir implican.

\begin{abstract}
Ay, ha desaparecido la fe, en la dignidad, singularidad, insustituibilidad humanas dentro de la escala de los seres, -el hombre se ha convertido en un animal, animal sin metáforas, restricciones ni reservas, él, que en su fe anterior era casi Dios («hijo de Dios», «hombre Dios»)... A partir de Copérnico el hombre parece haber caído en un plano inclinado, -rueda cada vez más rápido, alejándose del punto central -¿hacia dónde?, ¿hacia la nada?, ¿hacia el horadante sentimiento de su nada? (Nietzsche, 1995: 178)
\end{abstract}

Así, el ser humano pierde su capacidad de metaforizar su mundo, ya no es capaz, ni siquiera, de crear metáforas. Nietzsche señala que el embelesamiento por la ciencia, le impide al hombre apreciarse a sí mismo; al alejarse de sí, se aleja también de su capacidad creadora de metáforas. Entonces recurre a falsificaciones de falsificaciones. En su reflexión, Joseph Roth no pretende desalentarnos en nuestra incursión a través del mundo industrializado, tecnificado, él no está atacando ni a la tecnología, ni a las cortesías que ésta procura a la existencia del hombre, "No es que queramos hablar según piensa esa gente adocenada defensora de la idea de que la industria y la civilización son obra del infierno. ¡No!” (Roth, 2002: 28) Dice él. Él hace un reproche que está dirigido al hombre, por perder de vista la realidad y optar por el espejismo, por dejarse cegar por sombras que confieren certeza ficticia:

... nuestra saciedad no ha dejado de ser hambre, nuestra patria sigue siendo la falta de un hogar, y lo que llamamos realidad, sigue siendo engaño, pues todo cuanto denominamos conocimiento es mentira. Creemos beber de manantiales rebosantes y son fuentes secas, ellas mismas sedientas. (Roth, 2002: 32)

Difícil es imaginar que alguien vaya a renunciar al uso del teléfono una vez que se ha vuelto cotidiano. Al tener esa experiencia de "comunicación" puede suceder que ya no nos acordemos o que no conozcamos una vida sin telefonía, eso pasa prácticamente a muchos, mas ¿se puede hablar de verdadera comunicación?, ¿de cercanía? ¿de entendimiento?

[...] podemos hablar con otros a miles de kilómetros; pero ¿podemos entendernos? ¿Nos decimos la verdad cuando interponemos entre nosotros ese prodigio consistente en hacer oír nuestra voz a miles de kilómetros? Y cuando un amigo que se encuentra en Australia, habla «por el inalámbrico», según lo llaman, con su amigo que se halla en Colombia, el «milagro técnico» de poder escucharse, ¿impide, acaso, el engaño, la falsedad y la traición en su plática? ¿No es, por cierto, más fácil mentir cuando no nos 
vemos cara a cara? Y, aunque algún día llegue a poder ver la cara de mi amigo en El Cairo y él la mía en París, ¿nos conoceremos mejor que cuando nuestros cuerpos estaban frente a frente en una pequeña habitación?¿No ocurrirá, en cambio, que, llegado el caso, nos conoceremos todavía menos? (Roth, 2002: 33)

Para Nietzsche el hombre estaba atrapado en las redes del lenguaje, Con la tecnología, se entretejieron interminables redes de información, lo que evidentemente posibilita la incomunicación, por su inconmensurabilidad, logrando entonces que el diálogo sobre y donde hubo individuo ahora ya sólo haya redes.

Hemos de considerar que el hombre no puede vivir sin la mentira: "La vida la que necesita de ilusiones, vale decir, falsedades consideradas como verdades", (Vaihinger, 1990: 49) y "sería simpleza y necedad, según hemos dicho ya claramente, maldecir los inventos y la razón, de la que proceden, pues el inventor no ha hecho más que aplicar la razón, don de Dios.” (Roth, 2002: 37). Es preciso, pues, si queremos vivir, utilizar la mentira, la ilusión, la imagen y la representación, la ciencia y la tecnología, aunque, eso sí, con conciencia de lo que son; abrir los ojos a lo problemático y hermoso de la existencia para vivir intensamente, aprovechar los medios en pro de los fines. De ahí que, más que repartir información, datos, poner etiquetas y nombres, se procure un "involucramiento" con la propia vida, donde la metáfora de la representación nos proteja de la erradicación de la capacidad creadora.

El ser humano desarrolló creativamente lenguaje, metáfora y conocimiento, herramientas, técnica y útiles, ciencia y tencología; mas poco a poco cede su ser a sus inventos, porque la ciencia para Nietzsche, apunta al detrimento de la actividad creativa, al normar y domesticar la vida mediante la imposición y dominio de los artefactos. Entonces se produce el anquilosamiento del ser, se deja de lado la propia creatividad, se abandonan las ilusiones y el propio instinto creador:

Sí, se triunfa por el hecho de que hoy «la ciencia comienza a dominar sobre la vida». Es posible que esto llegue a ocurrir, pero, ciertamente, una vida controlada de esta manera no valdría gran cosa porque es mucho menos vida y garantiza mucho menos la vida para el futuro que la vida que dominaba, no a través del saber, sino por instintos y robustas ilusiones.(Nietzsche, 1994: 109)

Lo verdaderamente preocupante son las actitudes humanas: la ciencia y la tecnología son inocentes; preocupa la falta de compromiso y responsabilidad, la apatía e indiferencia con que el hombre deja de decidir y ser autoconsciente, la renuncia a su ser sí mismo. 
Nietzsche menciona, a propósito de la ciencia, que ésta tiene la intención de hacer más agradable la vida del hombre, sin embargo, ello no la exime de, al fin y al cabo creación humana, poseer un carácter dual, es decir, del mismo modo bien puede proveer de felicidad como de infelicidad al hombre. La cuestión que aquí nos debe preocupar, es el poder con que el hombre dota a esa creación suya al grado de que ésta tenga la aptitud de despojar al hombre de su dualidad, enajenarle al grado de alcanzar la estoicidad:

¿Cómo? ¿el objetivo último de la ciencia sería proporcionar al hombre la mayor cantidad posible de placer y la menor cantidad posible de desplacer? Pero iy si el placer y el desplacer se hallan atados juntos de tal modo que quien quiere la mayor cantidad posible de uno tiene que aceptar también la mayor cantidad posible del otro - que quien quiere aprender la jubilosa exultación tiene que prepararse también para la extrema desesperación?

¡En efecto, mediante la ciencia puede promoverse tanto un objetivo como el otro! Tal vez se la conozca hoy en día más aún por el poder que tiene de privar al hombre de sus alegrías y volverlo más frío, más rígido, más estoico. (Nietzsche, 2000: 72)

Entonces podría inferirse cómodamente que Nietzsche nos deja sin posibilidad, ya que, primero hace una fuerte crítica a la actividad cognitiva del hombre, asegurando que no es posible acceder al conocimiento mediante verdades absolutas y racionales; como si, por más malabares conceptuales que hagamos, estamos condenados al desconocimiento:

Los dioses condenaron a Sísifo a empujar sin cesar una roca hasta la cima de una montaña, desde donde la piedra volvería a caer por su propio peso. Pensaron, con cierta razón, que no hay castigo más terrible que el trabajo inútil y sin esperanza. (Camus, 2006: 155)

Para lanzar luego una fuerte crítica contra la ciencia; mas siendo cuidadosos, podemos darnos cuenta de la admiración que siente Nietzsche por la capacidad creativa del hombre. Es por ello que resulta lamentable que abandone la actividad inventiva, "La libre inventiva, que es facultad proteica, queda sometida a la necesidad" (Nicol, 2004: 115), para dejarse llevar por el efímero disfrute que le procura el uso de artificios, creados mediante el uso de la tecnología, deviniendo él mismo en un circuito cerrado a las posibilidades; el hombre deja de crear metáforas y se deja confundir por efímeros benefactores cuyo carácter está inmerso en la inmediatez y, termina con-fundiéndose, como si él mismo fuera parte de un mecanismo cerrado, que no tiene opción, donde sólo sube y baja permanentemente. 
En esta búsqueda insaciable por el bienestar, la humanidad fue más allá: aprendió a inventar útiles y herramientas a partir del uso de la técnica, desarrolló ciencia y tecnología, a partir de la cual puede dedicarse a producir artificios, artefactos y prótesis: todo ello orientado hacia la procuración de un "mayor y mejor bienestar y comodidad": Como si éstos fueran concebibles y realizables, de una vez y para siempre de manea inmutable.

Los benefactores que gracias a los nuevos desarrollos han sido susceptibles de ser producidos, han distraído a la humanidad de su tarea creativa, mudándola en funcional, el hombre desarrolló útiles e instrumentos, que más que facilitar su conservación y supervivencia, le suponen consecuencias que la ponen en peligro, me refiero a la riesgosa formación de necesidades, tal como apunta el filósofo austriaco Günther Anders (Anders, 2011: 171): se forman las necesidades; por lo que avoca su existencia a perseguirles; se dedica en cuerpo y alma a corretear una "comodidad" impuesta que es producida, descuidando con ello su ser creador, su ser autoconsciente, para subordinarse a un sistema orientado al sobreconsumo, que principalmente consume la vida del ser.

Empero aún en medio de lo que parece ser insalvable, está la condición indeterminada del ser humano, la que posibilita considerar que, si bien un Sísifo está condenado a subir su pesada roca a la montaña y verla caer por su propio peso permanentemente, cuenta con la posibilidad de hacer experiencia y asumir con plena conciencia cada vivencia, cada nueva posibilidad: de subir, de ver bajar; de bajar y tener que subir. Dotando cada vez de novedad, de sentido, único e irrepetible su vida:

Si el descenso se hace ciertos días con dolor, puede también hacerse con gozo. (Camus, 2006: 158)

Es él, Sísifo o el ser humano, quien hace su posibilidad con su aceptación o con su negación. Sólo él puede decidir someterse ante la ilusión que le producen las innovaciones, formándose mecánicamente: asimilándose al mecanismo, como “ ¡Un rostro que pena tan cerca de las piedras es ya de piedra!" (Camus, 2006: 157). O bien, puede decidir su posibilidad de vivir autoconsciente: asirla y hacerla creativamente, siéndole fiel a su propia existencia:

Pero Sísifo enseña la fidelidad superior que niega a los dioses y levanta las rocas. También él juzga que todo está bien. Este universo en adelante sin dueño no le parece estéril ni fútil. Cada uno de los granos de esa piedra, cada fragmento mineral de esa montaña llena de noche, forma por sí solo un mundo. La lucha por llegar a las cumbres basta para llenar un corazón de hombre. Hay que imaginarse a Sísifo feliz. (Camus, 2006: 160) 
Sólo porque puede decidir vivir la vida sin sometimiento ciego y servil. Precisamente porque no se trata de limitar-se en torno a un determinismo tecnológico, sino de reflexionar la conformación de las nuevas maneras de relacionarse del ser, en donde éste no pierda de vista su papel creador y constitutivo y no fungiendo como mero soporte al servicio de las tecnologías.

Optar pues, por recuperar la capacidad de ser creativo; recobrar la capacidad de crear metáforas, de recrearse ilusiones del conocimiento. Considerar que ni la técnica, ni la tecnología, ni la verdad, ni la mentira, ni las interpretaciones que brinda la filosofía, ni ninguna ciencia, son definitivos, ni determinantes de la condición humana: recordar que son creaciones meramente humanas que posibilitan y potencian la vida y no están a disfavor de ella, siendo ésta una decisión meramente humana, propia del corazón del hombre.

\section{BIBLIOGRAFÍA}

Anders, Günther. La obsolescencia del hombre. Vol I. "Sobre el alma en la época de la segunda revolución industrial. Valenica: Pre-Textos, 2011.

Camus, Albert. El mito de Sísifo. Madrid: Alianza Editorial, 2006.

Nicol, Eduardo. La agonía de Proteo. México: Herder, 2004.

Friedrich Nietzsche. Así habló Zaratustra. Trad. Andrés Sánchez Pascual, Madrid: Alianza Editorial,1989. El libro del filósofo. Madrid: TAURUS, 2000.

La genealogía de la moral. Trad. Andrés Sánchez Pascual, Madrid: Alianza Editorial, 1995.

Humano, demasiado humano. Trad. Carlos Vergara, Madrid: EDAF, 1984

Sobre la utilidad y los perjuicios de la historia para la vida. Trad. Dionisio Garzón. Madrid: EDAF, 2000.

Sobre verdad y mentira en sentido extramoral. Trad. Luis Ml. Valdés y Teresa Orduña. Madrid: Tecnos, 1990.

Roth, Joseph. El Anticristo. Trad. José Luis Gil Aristu. Barcelona: Ediciones Península, 2002.

Schopenhauer, Arthur. Parera y Paralipómena I, II. Trad. Pilar López de Santamaría, 2 vol. Madrid: Trotta, 2006. 


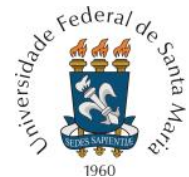

PROGRAMA DE PÓS-GRADUAÇÃO EM COMUNICAÇÃO DA UNIVERSIDADE FEDERAL DE SANTA MARIA

Original recebido em: 30 de março de 2019

Aceito para publicação em: 10 de maio de 2019

\section{(2) $\odot \Theta(0)$}

Esta obra está licenciado com uma Licença

Creative Commons Atribuiç̧ão-NãoComercial-CompartilhaIgual 4.0 Internacional 